\title{
BENTUK DAN PROSES PEMBENTUKAN BAHASA PROKEM PARA PEKERJA MANYENG DI DESA GARUNG LOR KECAMATAN KALIWUNGU KABUPATEN KUDUS
}

\author{
Much Arsyad Fardani ${ }^{1}$, Dwiana Asih Wiranti ${ }^{2}$ \\ arsyad.fardhani@umk.ac.id; wiranti@unisnu.ac.id
}

Prodi Pendidikan Guru Sekolah Dasar, Fakultas Keguruan dan Ilmu Pendidikan Universitas Muria Kudus

Pendidikan Guru PAUD, Fakultas Tarbiyah dan Ilmu Kependidikan

Universitas Islam Nahdlatul Ulama Jepara

\begin{abstract}
Abstrak
Tujuan penelitian ini adalah menjabarkan bentuk dan proses pembentukan bahasa prokem para pekerja manyeng di Desa Garung Lor, Kecamatan Kaliwungu, Kabupaten Kudus. Metode penelitian yang digunakan adalah menggunakan metode deskriptif kualitatif. Hasil dari penelitian ini adalah ditemukan tiga bentuk bahasa prokem yang digunakan para pekerja manyeng di Desa Garung Lor, Kudus. Ketiga bentuk tersebut, antara lain: 1) bentuk kata tunggal, 2) bentuk kata kompleks, dan 3) bentuk sapaan. Proses pembentukan dari ketiga kategori memiliki perbedaan. Pada bentuk kata tunggal dan kompleks proses pembentukannya dengan menambahkan suku kata ask pada vokal terakhir suatu kata. Sementara itu, proses pembentukan bentuk sapaan tidak menggunakan rumus tertentu melainkan lebih pada manasuka.
\end{abstract}

Kata Kunci: bentuk, proses pembentukan, bahasa prokem, pekerja manyeng.

\begin{abstract}
The aim of this research is to describe the from and process of forming prokem language of manyeng workers in Garung Lor Village, Kaliwungu, Kudus Regency. The research method used descriptive qualitative methods. The result of this research found that there are three kinds from of prokem language that use by manyeng workers in Garung Lor Village, Kudus. As follows: 1) form of single word, 2) form of comnplex word, and 3) form of greeting. The formation process of the three categories has differences. In a single and complex word from the process of formation is by adding the "ask" syllable to the last vowel of a word. Meanwhile, the process of forming the greeting form does not require a specific formula but prefer to manasuka.
\end{abstract}

Keywords: form, process of formation, prokem lenguage, manyeng workers

\section{PENDAHULUAN}

Bahasa merupakan alat komunikasi utama manusia yang memiliki beragam karakteristik. Salah satunya adalah bahasa bersifat arbitrer, oleh sebab itu bahasa berkembang dengan cepat seiring dengan perkembangan zaman. Perkembangan zaman yang sangat pesat berakibat pada pesatnya berkembangan ragam bahasa yang muncul. Ragam bahasa yang muncul biasanya bersifat khusus karena hanya dimengerti oleh kelompok tertentu. Salah satu contoh dari ragam bahasa tersebut adalah bahasa slang atau bahasa prokem.

Sumarsono (2002) mengatakan bahwa dalam masyarakat tutur penggunaan bahasa slang atau bahasa prokem telah ada sejak tahun 1970-an. Awal mulanya, bahasa slang juga dikenal dengan bahasa prokem. 
Pembentukan bahasa prokem awal mulanya dimaksudkan sebagai kode atau sandi yang hanya dimengerti oleh kelompoknya saja. Pada era lampau, penggunaan bahasa prokem identik digunakan para pencopet, bandit, dan preman. Seiring perkembangan zaman, bahasa prokem mulai merambah pada kelompok masyarakat umum. Salah satu kelompok masyarakat yang menggunakan bahasa prokem dalam berkomunikasi adalah para pekerja manyeng yang ada di Desa Garung Lor, Kecamatan Kaliwungu, Kabupaten Kudus.

Profesi tukang manyeng adalah sebutan lain untuk para pencari barang bekas. Profesi ini sebagian besar digeluti oleh warga di desa Garung Lor, Kudus. Dalam kegiatan sehariharinya mereka menggunakan bahasa sandi yang sering kita kenal dengan bahasa prokem. Penggunaan bahasa prokem ini sudah berlangsung lama dan terjadi karena keisengan dari para pekerja manyeng yang melihat adanya penggunaan bahasa prokem di daerah lain. Namun, karena bahasa ini memiliki keunikan, maka bahasa ini masih bertahan untuk digunakan hingga sekarang. Keunikan dari bahasa prokem para pekerja manyeng terletak pada penggunaannya.

Pada umumnya, bahasa prokem merupakan bahasa yang digunakan sebagai bentuk identitas suatu kelompok. Selain sebagai identitas kelompok, bahasa prokem para pekerja manyeng digunakan sebagai sarana komunikasi dalam menjalankan pekerjaannya. Selama proses tawar menawar dengan konsumen, para pekerja manyeng biasanya berdiskusi dengan rekannya untuk menentukan harga beli yang cocok untuk barang yang akan dibelinya. Pada saat inilah bahasa prokem digunakan. Berdasarkan hal tersebut, permasalahan yang akan dipecahkan adalah: 1) bagaimana bentuk bahasa prokem para pekerja manyeng di Desa Garung Lor, Kaliwungu, Kudus dan 2) Bagaimana proses pembentukan bahasa prokem pekerja manyeng di Desa Garung Lor, Kudus.

\section{KAJIAN TEORI}

Konsep-konsep teori yang digunakan sebagai landasan dalam penelitian ini adalah, 1) variasi bahasa, 2) bahasa prokem, dan 3) proses pembentukan bahasa prokem. Ketiga teori ini digunakan untuk mengupas temuan-temuan yang ada di lapangan. Melalui teori-teori tersebut dapat ditemukan bentuk dan proses pembentukan dari bahasa prokem yang digunakan para pekerja manyeng yang ada di Desa Garung Lor Kabupaten Kudus.

\section{Variasi Bahasa}

Bahasa merupakan sarana komunikasi antar manusia. Melalui bahasa segala maksud dan tujuan dapat diterima dengan baik oleh setiap manusia. Intensitas interaksi antar manusia akan menimbulkan munculnya berbagai variasi bahasa yang digunakan oleh masyarakat. Suwito (1991) menyatakan bahwa variasi bahasa adalah sejenis ragam 
bahasa yang pemakaiannya disesuaikan dengan fungsi dan situasinya tanpa mengabaikan kaidahkaidah pokok yang berlaku dalam bahasa yang bersangkutan. Variasi bahasa timbul akibat adanya interaksi sosial yang beragam dalam sebuah masyarakat. Waridah (2015) mengatakan bahwa terbentuknya variasi bahasa ditentukan oleh beberapa faktor, yaitu faktor tempat, faktor sosiokultural, faktor situasi, faktor waktu, dan faktor medium pengungkapan (bahasa lisan dan tulisan). Kesesuaian pemilihan variasi bahasa menjadikan komunikasi yang dilakukan akan berjalan sesuai dengan tujuan yang diharapkan. Alwasilah (1993) menjelaskan bahwa dalam proses komunikasi yang sebenarnya, setiap penutur tidak pernah setia pada satu ragam atau dialek tertentu saja.

Ada berbagai macam variasi bahasa yang timbul akibat interaksi sosial kemasyarakatan. Chaer (2006) membagi variasi bahasa ke dalam beberapa kelompok, yaitu ragam bahasa perseorangan, ragam bahasa sekelompok masyarakat dari wilayah tertentu, ragam bahasa berdasarkan golongan sosial, ragam bahasa dalam kegiatan suatu bidang tertentu, ragam bahasa situasi formal, ragam bahasa informal, serta ragam bahasa lisan dan tulis. Variasi bahasa akan tampak jelas dalam dialog yang digunakan oleh anggota masyarakat, misalnya dalam proses berkomunikasi yang dilakukan sehari-hari (Nurunnisa, 2013). Dari beberapa pendapat di atas tampak beberapa ragam bahasa yang timbul diakibatkan adanya interaksi sosial antar manusia.

Menurut Chaer (1994) idiolek merupakan variasi bahasa yang bersifat perseorangan Setiap individu memiliki ragam bahasa tersendiri yang sering tidak disadarinya. Ragam idiolek biasanya menjadi penciri dari setiap individu. Sementara itu, ragam bahasa yang digunakan oleh sekelompok anggita masyarakat dari wilayah tertentu sering diesbut dengan dialek. Dialek lebih memusatkan pada variasi atau perbedaan bahasa berdasarkan faktor geografi yang telah ada (Zulaeha, 2010). Perbedaan struktur geografis biasanya menjadi penyebab terbentuknya dialek pada masyarakat penuturnya. Sebagai contoh, dalam bahasa Jawa dikenal ada dialek Banyumasan, Tegal, Kudus, Pati, Semarangan, dan sebagainya.

Kelompok variasi ragam bahasa selanjutnya adalah ragam bahasa yang digunakan oleh sekelompok anggota masyarakat dari sosial tertentu disebut sosiolek. Sosiolek juga disebut sebagai dialek sosial, yaitu variasi bahasa yang berkenaan dengan status, golongan, dan kelas sosial para penuturnya (Chaer, 1994). Sebagai contoh bahasa yang digunakan oleh kalangan pelajar akan berbeda dengan bahasa yang digunakan oleh anak jalanan.

Ragam bahasa dalam situasi formal dan informal ditengarai dengan waktu dan situasi digunakannya bahasa tersebut. Bahasa yang digunakan dalam situasi resmi biasanya disebut dengan istilah bahasa 
baku atau bahasa formal. Dalam situasi tidak resmi ragam bahasa yang digunakan disebut dengan ragam bahasa nonbaku atau informal.

$$
\text { Variasi ragam bahasa }
$$

selanjutnya adalah ragam bahasa tulis dan lisan. Ragam bahasa tulis dan lisan sangatlah berbeda. Bahasa tulis harus memperhatikan penggunaan struktur kalimat dan penggunaan tanda baca agar maksud dan tujuannya dapat ditangkap dengan baik. Sementara bahasa lisan harus diiringi dengan mimik wajah, gerakgerik anggota tubuh, dan intonasi dalam pengucapannya agar informasi yang disampaikan dapat diterima dengan baik.

Sejalan dengan pendapat Chaer di atas, Chaer dan Agustina (2004) mengelompokkan variasi bahasa menjadi empat kelompok, yaitu 1) variasi bahasa dari segi penutur, 2) variasi bahasa dari segi pemakaian, 3) variasi bahasa dari segi keformalan, dan 4) variasi bahasa dari segi sasaran.

Variasi bahasa dari segi penutur dibagi menjadi empat jenis, yaitu idiolek, dialek, kronolek atau dialek temporal, dan sosiolek. Variasi idiolek berkaitan dengan ujaran individu yang unik dan berbeda-beda. Sementara dialek merupakan suatu suatu ragam bahasa yang berkaitan dengan sekelompok penutur tertentu, jumlahnya relative dan berada pada suatu wilayah tertentu. Kronolek merupakan variasi bahasa yang digunakan oleh sekelompok sosial pada masa tertentu, sedangkan sosiolek adalah sebuah dialek sosial yang berkenaan dengan status golongan atau kelas sosial penutur.

Variasi bahasa dari segi pemaikaian sering disebut dengan fungsiolek, ragam atau register. Variasi ini biasanya digunakan berdasarkan bidang penggunaannya, gaya, dan sasaran penggunaan. Sementara variasi bahasa dari segi keformalan merupakan jenis bahasa berdasarkan situasi penggunaan bahasa tersebut.

Variasi bahasa dari segi sarana disebut juga dengan ragam lisan dan tulis. Adanya ragam bahasa tersebut didasarkan pada perbedaan wujud dan struktur diantara keduanya. Berdasarkan hal tersebut, timbulnya variasi bahasa tidak bisa dilepaskan dari adanya interaksi sosial antar manusia. Masyarakat yang heterogin akan memunculkan berbagai macam variasi bahasa yang digunakan dilingkungan masyarakat tersebut. Chaer dan Agustina (2004) berpendapat, bahwa terjadinya variasi atau ragam bahasa diakibatkan adanya keberagaman sosial penutur bahasa dan keberagaman fungsi bahasa.

\section{Bahasa Prokem}

Seiring perkembangan zaman, mulai banyak bermunculan modifikasi bahasa yang dibuat oleh komunitas atau sekelompok masyarakat. Semakin terbukanya jaringan komunikasi dengan lingkungan luar, menjadi pendorong munculnya variasivariasi bahasa baru yang ada di masyarakat. Modifikasi bahasa yang dilakukan umumnya bersifat internal 
komunitas saja. Hanya anggota kelompok atau komunitas saja yang bisa menggunakan dan tahu maksud dari bahasa tersebut. Modifikasi bahasa yang terjadi sering disebut dengan bahasa prokem.

Sumarsono

mendefinisikan bahasa prokem sebagai salah satu tuturan remaja yang khas dan muncul di Jakarta. Kita ketahui bahwa awal mula munculnya istilah bahasa prokem beasal dari Jakarta. Melihat kondisi masyarakat Jakarta yang beranekaragam akan dengan mudah memunculkan adanya bahasa prokem.

Sementara itu, Partana dan Sumarsono (2008: 154) mengartikan prokem merupakan bahasa yang awalnya digunakan oleh kaum pencoleng, pencopet, bandit, dan sebangsanya yang memiliki fungsi sebagai bahasa rahasia, namun sekarang bahasa tersebut digunakan oleh remaja khususnya Jakarta. Keberadaan bahasa prokem biasanya menjadi penanda keberadaan suatu kelompok atau komunitas. Dari beberapa pemaparan para ahli, dapat disimpulkan bahwa bahasa prokem merupakan bentuk bahasa modifikasi yang digunakan para kalangan remaja untuk menunjukkan jati diri mereka.

\section{Morfologi}

Proses pembentukan kata terjadi dikarenakan adanya proses morfologi. Morfologi merupakan salah satu bidang ilmu linguistik yang mengkaji tentang bentuk dan proses pembentukan kata. Istiqomah (2018) mendefinisikan morfologi sebagai bagian dari ilmu bahasa yang mengkaji seluk beluk bentuk kata serta pengaruh perubahan-perubahan bentuk kata terhadap golongan dan arti kata. Sejalan dengan Istiqomah, Suhardi (2008) mengartikan morfologi sebagai salah satu cabang ilmu bahasa yang mengkaji masalah struktur kata. Dari dua pendapat tersebut dapat ditarik kesimpulan bahwa morfologi adalah salah satu ilmu bahasa yang mengkaji tentang bentuk kata dan proses pembentukan kata.

Pembentukan kata dapat dilakukan dengan beberapa proses, diantaranya adalah dengan memberikan imbuhan atau afiksasi dan pengulangan atau reduplikasi. Dalam ilmu bahasa, proses pembentukan kata disebut dengan proses morfologis. Proses morfologis merupakan proses pembentukan kata dari satuan lain yang merupakan bentuk dasar (Ramlan, 2001). Kasus yang ditemukan pada bahasa prokem para pekerja manyeng adalah dengan memberikan imbuhan ask pada setiap katanya. Kridalaksana (2008) menjelaskan proses morfologis sebagai proses yang mengubah leksem menjadi kata. Beberapa proses morfologis tersebut antara lain derivasi zero, afiksasi, reduplikasi, abreviasi, komposisi, dan derivasi balik.

Dervasii zero, menurut Kridalaksana (2008) merupakan proses yang mengubah leksem menjadi kata tanpa penambahan ataupun pengurangan. Dengan kata lain, proses derivasi zero merupakan bentuk kata dasar. Afiksasi merupakan 
penambahan pada kata dasar. Ramlan (2001) menyebutkan afiksasi memiliki tiga proses perubahan, yaitu prefiks, infiks, dan sufiks atau yang sering kita kenal dengan awalan, sisipan, dan akhiran.

Reduplikasi merupakan proses dan hasil pengurangan satuan bahasa sebagai alat fonologis atau gramatikal (Kridalaksana, 2008). Pembentukan kata melalui proses reduplikasi dilakukan dengan mengulang bentuk dasarnya. Selanjutnya, Kridalaksana (2008) menyebutkan terdapat tiga jenis reduplikasi, yaitu reduplikasi fonologis, reduplikasi morfemis, dan reduplikasi sintaksis. Reduplikasi fonologis terjadi tanpa merubah makna dikarenakan tidak adanya pengulangan leksem. Reduplikasi morfemis disertai dengan perubahan makna gramatikal sebagai akibat dari pengulangan leksem. Sementara reduplikasi sintaksis adalah proses yang terjadi sebagai akibat dari pengulangan leksem sehingga menjadi satuan kata baru.

\section{Proses Pembentukan Bahasa Prokem}

Ada banyak cara dapat digunakan untuk membentuk bahasa prokem. Setiap kelompok memiliki cara tersendiri untuk membentuk bahasa prokem. Sumarsono (2002) dalam penelitiannya mengemukakan ada beberapa cara yang digunakan oleh para remaja untuk memodifikasi bahasa tutur mereka, antara lain: menyisipkan konsonan vokal $\mathrm{V}+$ vokal, penggantian suku kata akhir dengan -sye, membalik fonem-fonem dalam kata (ragam walikan), dan variasi dari ragam walikan. Proses modifikasi yang dilakukan untuk membuat bahasa prokem menjadi kesepakatan antar anggota dalam kelompoknya. Tidak adanya aturan baku dalam proses modifikasi bahasa menjadikan bahasa prokem antar kelompok memiliki cara yang berbeda-beda. Perbedaan tersebut menjadikan kekhasan dari bahasa yang mereka gunakan.

\section{METODE PENELITIAN}

Penelitian ini menggunakan pendekatan teoretis dan metodologis. Pendekatan teoretis yang digunakan adalah pendekatan sosiolingusitik. Pemilihan pendekatan sosiolinguistik dikarenakan dalam penelitian ini mengkaji bahasa dan hubungan penggunaannya dalam masyarakat. Dalam hal ini, peneliti melakukan analisa bentuk dan proses pembentukan bahasa prokem yang digunakan komunitas pekerja manyeng yang menjadi salah satu dari variasi bahasa yang ada.

Secara metodologis, penelitian ini menggunakan pendekatan deskriptif kualitatif. Data yang diperoleh selama penelitian akan disajikan secara deskriptif. Bogdan dan Tylor (dalam Moleong, 2010) menyatakan bahwa pendekatan kualitatif merupakan pendekatan penelitian yang menghasilkan data deskriptif berupa kata-kata tertulis atau lisan yang dapat diamati. Penelitian ini difokuskan pada percakapan yang dilakukan oleh para 
pekerja manyeng untuk mengetahui bentuk dan proses pembentukannya.

Data pada penelitian ini diperoleh melalui informan, dalam hal ini adalah para pekerja manyeng. Data yang diperoleh dari infroman berupa data percakapan yang dilakukan antar pekerja manyeng dalam berbagai situasi. Metode pengumpulan data menggunakan metode simak dan cakap. Metode simak merupakan metode yang digunakan dalam penyediaan data dengan cara peneliti melakukan penyimakan penggunaan bahasa (Moleong, 2010). Pada penelitian ini peneliti terlibat dalam percakapan dimaksudkan untuk menyadap percakapan informan pada saat menggunakan bahasa prokem. Metode simak memiliki beberapa teknik simak, antara lain teknik simak bebas libat cakap, teknik rekam, dan teknik catat.

Proses pengambilan data dilakukan dengan cara peneliti terlibat dalam percakapan yang terjadi. Keterlibatan peneliti tidak sepenuhnya, melainkan hanya pada percakapan yang menggunakan bahasa Jawa pada umumnya. Sementara ketika terjadi percakapan yang mengandung bahasa prokem peneliti tidak terlibat. Proses ini dimaksudkan agar kewajaran dari tuturan yang dilakukan tetap terjaga. Penggunaan teknik ini bebarengan dengan penggunaan teknik rekam. Selama percakapan terjadi, peneliti melakukan perekaman percakapan baik yang menggunakan bahasa Jawa pada umumnya ataupun pada saat menggunakan bahasa prokem. Teknik ini dilakukan tanpa sepengetahuan informan.

Setelah semua data diperoleh, dilakukan pencatatan hasil rekam percakapan menggunakan teknik catat. Data yang diperoleh selama proses perekaman dipindahkan ke dalam kartu data untuk kemudian dikelompokkan berdasarkan bentuknya agar memudahkan proses pengolahan data. Data yang sudah dikelompokkan kemudian diterjemahkan ke dalam bahasa Jawa untuk mengetahui makna, bentuk, dan proses pembentukannya.

Metode yang kedua adalah metode cakap. Metode ini sama dengan metode wawancara, karena didalamnya harus ada interaksi antara peneliti dan sumber data. Metode ini digunakan untuk menggali informasi yang tidak ditemukan dalam tuturan. Selain itu, metode ini juga digunakan untuk mengetahui beberapa kosa kata dalam bahasa prokem yang tidak dimengerti oleh peneliti. Metode cakap ini digunakan dengan menggunakan teknik cakap semuka, teknik rekam, dan teknik catat.

Teknik cakap semuka yaitu melakukan percakapan secara langsung dengan informan. Percakapan dilakukan dengan tujuan untuk memperoleh informasi lebih banyak lagi. Teknik cakap semuka didukung dengan teknik rekam dan teknik catat. Teknik rekam dilakukan secara sadar dan diketahui oleh informan. Setelah proses pencarian informasi melalui teknik cakap 
semuka selesai dilanjutkan menghimpun data yang diperoleh menggunakan teknik catat. Semua data yang ada dalam rekaman yang berkaitan dengan bahasa prokem dicatat untuk mempermudah proses penyusunan dan analisis data.

Setelah semua data diperoleh dilanjutkan dengan proses analisa data. Analisa data dalam penelitian ini menggunakan metode agih. Metode agih menurut Sudaryanto (1993) merupakan metode yang alat penentunya merupakan bagian dari bahasa tersebut. Alat penentu yang digunakan dalam penelitian ini adalah kata-kata dalam bahasa prokem pekerja manyeng di Desa Garung Lor. Metode agih digunakan untuk meneliti bentuk dan proses pembentukan bahasa prokem pekerja manyeng.

\section{HASIL DAN PEMBAHASAN}

Bahasa prokem merupakan bahasa remaja yang berkecenderungan mencetak atau merangkai bahasanya sendiri sebagai lambang suatu kelompok. Penggunaan bahasa prokem ditujukan sebagai penggambaran identitas pribadi kelompoknya. Sekelompok pekerja manyeng di Desa Garung Lor, Kaliwungu, Kudus memiliki bahasa prokem yang digunakan sebagai identitas keberadaan mereka. Penggunaan bahasa prokem telah disepakati bersama agar memudahkan mereka berkomunikasi satu sama lain. Dari penelitian yang telah dilakukan, ditemukan beberapa kosa kata yang digunakan dalam bahasa prokem para pekeraja manyeng.

\section{Bentuk Bahasa Prokem}

Penelitian ini menemukan tiga bentuk kata dalam bahasa prokem yang digunakan para pekerja manyeng di Desa Garung Lor, Kaliwungu, Kudus. Pengklasifikasian tersebut antara lain: (1) kosa kata bahasa prokem bentuk tunggal, (2) Kosa kata bahasa prokem bentuk kompleks, dan (3) kosa kata bahasa prokem bentuk sapaan. Ketiga bentuk tersebut akan diuraikan di bawah ini.

Tabel 1. Kosa kata bahasa prokem bentuk tunggal

\begin{tabular}{|c|c|c|c|c|}
\hline No & Kata & Fonetik & Makna Jawa & Makna Bahasa Indonesia \\
\hline 1 & Ajaska & [ojasko] & aja & jangan \\
\hline 2 & Akaski & [akaski] & aki & accu \\
\hline 3 & Akasku & [akasku] & aku & aku \\
\hline 4 & Anaska & [onasko] & ana & ada \\
\hline 5 & Apaska & [opasko] & apa & apa \\
\hline 6 & Ataskum & [ataskum] & atum & plastik \\
\hline 7 & Awaskan & [awaskan] & awan & siang \\
\hline 8 & Bacaskin & [bacaskIn] & bacin & bau tak sedap \\
\hline
\end{tabular}




\begin{tabular}{lllll}
9 & Ayasku & [ayasku] & ayu & cantik \\
\hline 10 & Dhuwaskit & [duwaskIt] & dhuwit & uang \\
\hline 11 & Gelaskem & [gəlaskəm] & gelem & mau \\
\hline 12 & Baraskang & [baraskan] & barang & barang \\
\hline 13 & Kowaske & [kowaske] & kowe & kamu \\
\hline 14 & Kerjaska & [kərjasko] & kerja & kerja \\
\hline 15 & Laraskang & [laraskay] & larang & mahal \\
\hline 16 & Muraskah & [muraskah] & murah & murah \\
\hline 17 & Oraska & [oraska] & ora & tidak \\
\hline 18 & Piraska & [pirasko] & pira & berapa \\
\hline 19 & Rugaski & [rugaski] & rugi & rugi \\
\hline 20 & Tawaska & [tawasko] & tawa & tawar \\
\hline 21 & Tukasku & [tukasku] & tuku & beli \\
\hline
\end{tabular}

Kosa kata pada tabel 1 tersebut belum mendapatkan merupakan jenis bahasa prokem imbuhan, pengulangan, dan bentuk tunggal. Bahasa prokem singkatan. Kata-kata tersebut bentuk tunggal adalah bentuk kata- berasal dari kata dasar yang kata prokem yang belum mengalami secara langsung mendapatkan proses morfologis. Proses morfologi modifikasi sehingga berbentuk kata yang dimaksud adalah kata-kata dalam bahasa prokem.

\section{Tabel 2. Kosa kata bahasa prokem bentuk kompleks}

\begin{tabular}{|c|c|c|c|c|}
\hline No & Kata & Fonetik & Makna Jawa & Makna Bahasa Indonesia \\
\hline 1 & Ditembaskel & [ditembaskel] & ditembel & Ditambal \\
\hline 2 & Ngumbaske & [yumbaske] & ngumbe & Minum \\
\hline 3 & Angaskele & [ayaskele] & angel & Susah \\
\hline 4 & Baskosku & [baskosku] & bosku & Bosku \\
\hline 5 & Hapaskene & [hapaskene] & hapene & Hpnya \\
\hline 6 & Modhaskale & [moḍaskale] & modhale & Modalnya \\
\hline 7 & Tipaskine & [tipaskine] & tipine & Tvnya \\
\hline 8 & Wegaskahan & [wəgaskahan] & wegahan & Pemalas \\
\hline 9 & Ketempaskuhan & [kətəmpaskuhan] & ketempuhan & Ganti rugi \\
\hline 10 & Nempaskuhi & [nəmpaskohi] & nempuhi & Mengganti \\
\hline 11 & laskas-laskasan & [laskas laskasan] & las-lasan & Dilas \\
\hline 12 & waskong-waskong & [waskıy waskøy] & wong-wong & Orang-orang \\
\hline
\end{tabular}

Kosakata yang terdapat pada tabel 2 merupakan jenis kosakata bahasa prokem bentuk kompleks. Bentuk kompleks merupakan bentuk kata yang sudah mengalami proses morfologis. Proses morfologis yang ditemukan dalam penelitian hanyalah proses afiksasi dan reduplikasi. Proses afiksasi merupakan proses perubahan kata dasar menjadi kata jadian dengan menambahkan imbuhan. Proses afiksasi ini meliputi, prefiks 
"awalan", sufiks "akhiran", dan konfiks "awalan dan akhiran".

(1)Konteks: P1， P2， dan P3 membicarakan barang yang akan dibelinya.

$\mathrm{P}$

$\begin{array}{lr}\text { : "Ndhul, } & \text { ajaska } \\ \text { gelaskem. } & \text { Tawaska } \\ \text { manaskeh" } & \end{array}$

"Ndhul, aja gelem. Tawa maneh."

"Ndhul, jangan mau. Tawar lagi. ${ }^{\text {ee }}$

P2 : "Hayo, njalaskuk laraskang kok"

"Hayo, njaluk larang kok."

"Mintanya mahal kok."

P3 : "Oraska ngrasakna angaskele waskong

kerjaska."

"Ora ngrasakna angele wong kerja."

"Tidak merasakan susahnya orang kerja. ${ }^{\text {ce }}$

Contoh percakapan di atas menunjukkan penggunaan bahasa prokem bentuk kompleks. Bentuk kompleks yang digunakan adalah hasil proses afiksasi dengan menambahkan akhiran (sufiks) pada setiap kata dasarnya. Kata angaskele "susah" merupakan bentuk dasar dari kata angaskel yang mendapat akhiran $\quad\{-\mathrm{e}\}$ Contoh lain penggunaan bentuk prokem kompleks hasil afiksasi dapat dilihat pada contoh percakapan di bawah ini.

(2) Konteks: P1 dan P2 membicarakan temannya.

P1 : "Agus nang ndi mau?"
"Agus dimana tadi?"

P2 : "Sek mubaskeng paling."

"Sek mubeng paling."

"Mungkin masih keliling."

P1 : "Cah kae ning manyeng bejanan kok."

"Anak itu kalau pergi manyeng selalu

beruntung."

P2 : "Bejaska piyaske?"

"Beja piye?"

"Beruntung bagaimana?"

P1 : "Bejaska a... mesti nutaskup modhaskale."

"Beja a... mesthi nutup modhale."

"Beruntung, selalu bisa menutup modalnya. ${ }^{\text {ee }}$

Pada percakapan di atas terdapat beberapa penggunaan kata dalam bahasa prokem. Kata-kata tersebut antara lain mubaskeng, bejaska, piyaske, nutaskup, dan modhaskale. Kata mubaskeng, bejaska, piyaske, dan nutaskup merupakan kata dalam bahasa prokem berbentuk tunggal. Sementara kata modhaskale merupakan kata dalam bahasa prokem bentuk kompleks. Perubahan morfologis yang terjadi adalah terdapatnya imbuhan berupa akhiran (sufiks). Kata modhaskale merupakan bentuk dasar dari kata modhaskal yang mendapatkan akhiran $\{-\mathrm{e}\}$. selain mendapatkan akhiran (sufiks) terdapat kata dalam bahasa prokem yang mendapatkan awalan (Prefiks). Bentuk kompleks setelah mendapatkan awalan dapat dilihat pada contoh percakapan di bawah ini. 
(3) Konteks: P1 bertanya kepada P1 mengenai ganti rugi.

P1 : "Lha nek ana baskan
bedhaskah
piyaske Bred?"
"Lha ne kana ban bedhah piye
Bred?e
"Lha kalau ada ban
yang bocor bagaimana Bred?"e
P2 : "Ya ditembaskel a Bred."
"Ya ditembel a Bred."
"Ya ditambal Bred."

$\mathrm{P} 1$ : "Lha nek helaskem

ilaskang?"

"Lha nek helem ilang?"

"Kalau helm yang hilang?"

ketempaskuhan a Bred.

Wong helaskem pecaskah wae nempaskuhi, apa maneh ilaskang."

"Ya ketempuhan a Bred. Wong helem

pecah wae nempuhi, apa maneh ilang."

"Harus mengganti Bred.

Helm pecah

saja harus diganti, apalagi hilang."

P1 : "Rugaski a ikasku?"

"Rugi a iku?"e

"Rugi kalau begitu ya?e
Konteks percakapan di atas dilakukan di salah satu tempat penitipan sepeda. Pekerja manyeng memiliki sampingan menjaga tempat titipan sepeda karyawan salah satu pabrik rokok yang ada di desanya. Pada konteks percakapan di atas dapat ditemukan beberapa kata yang menggunakan bahasa prokem, antara lain: baskan, bedhaskah, piyaske, ditembaskel, helaskem, ilaskang, ketempaskuhan, pecaskah, nempaskuhi, rugaski, dan ikasku. Dari beberapa kata dalam bahasa prokem menggunakan bentuk kompleks hasil dari afiksasi. Proses afiksasi yang digunakan berbentuk awalan (prefisk) terdapat pada kata ditembaskel "ditambal". Kata ditembaskel memiliki bentuk dasar tembaskel yang mendapatkan awalan $\{$ di- $\}$. Selain penambahan prefiks, ditemukan pula penggunaan kata kompleks hasil dari penambahan konfisk (awalan dan akhiran). Kata yang mengalami penambahan konfiks adalah kata ketempaskuhan. Kata tersebut memiliki kata dasar tempaskuh yang mendapatkan konfiks \{ke-/an\}.

Tabel 3. Kosa kata bahasa prokem bentuk sapaan

\begin{tabular}{llll}
\hline No & Kata & Fonetik & \multicolumn{1}{c}{ Makna } \\
\hline 1 & Bred & [bred] & Bentuk lain dari kata bro \\
\hline 2 & Lang & {$[$ lap] } & Sapaan untuk seseorang karena suka bepergian \\
\hline 3 & Ndhes & [nḍcs] & Bentuk sapaan bebas dalam bahasa Jawa \\
\hline 4 & Ndhul & [nḍol] & Berasal dari kata "gundhul" memiliki makna mengarah \\
\hline
\end{tabular}


Bentuk bahasa prokem yang ketiga adalalah bentuk sapaan. Bentuk sapaan merupakan bentuk bahasa prokem yang digunakan untuk panggilan seseorang yang ada dalam kelompok pengguna bahasa prokem, dalam hal ini para pekerja manyeng di Desa Garung Lor, Kaliwungu, Kudus. Bentukbentuk sapaan ini hanya dimengerti oleh anggota dalam kelompok para pekerja manyeng saja. Berikut beberapa contoh penggunaan bahasa prokem bentuk sapaan dalam sebuah percakapan yang mereka lakukan.

(4) Konteks: P1 menyapa P2 yang sedang malas-masalan.

P1 : "Ndhes, kowaske oraska mangjkaskat manyaskeng?"

"Ndhes, kowe ora mangkat manyeng?"

"Ndhes, kamu tidak berangkat manyeng?

P2 : "Mengkasko, akasku jek malaskes."

"Mengko, aku jek males."

"Nanti, saya masih malas."

P1 : "Halah, bocaskah kok wegaskahan."

"Halah, bocah kok wegahan."

"Jadi orang kok malas."

P2 : "Lha piyaske?

Kayanaske sepaski.

Tiwaskas kesaskel."

"Lha piye? Kayane sepi. Tiwas kesel."

"Bagaimana lagi?

Sepertinya lagi sepi.
Percuma hanya dapat lelah saja."

Bentuk prokem sapaan pada tuturan di atas terdapat pada kata ndhes. Kata sapaan tersebut dalam proses pembentukannya mengacu pada istilah tertentu. Istilah ndhes diambil dari kata gondhes. Penggunaan kata ini disebabkan karena adanya keakraban antar lawan bicara. Bentuk sapaan lain dapat ditemukan dalam contoh percakapan di bawah ini.

(5) Konteks: P1 mengajak P2 berangkat kerja.

P1 : "Lang, mangkaskat manyaskeng yuk."

"Lang, mangkat manyeng yuk."

"Lang, ayo kita berangkat manyeng."

P2 : "Ya, angger ndhisik. Akasku mangkaskat rada awaskan."

"Ya, angger mangkat ndhisik. Aku mangkat rada awan."

"Berangkat duluan saja. Aku agak siang berangkatnya."

Kata Lang merupakan bentuk kata sapaan dalam bahasa prokem para pekerja manyeng di Desa Garung Lor, Kudus. Kata Lang merupakan bentuk kependekan dari kata bolang. Pemilihan kata ini didasarkan karena kebiasaan salah satu anggota dalam kelompok pekerja manyeng yang senang berpetualang ke berbagai daerah. Kegiatan petualangan dilakukan atas 
dasar ingin menambah pengalaman yang berhubungan dengan pekerjaan yang dilakukannya. Bentuk sapaan yang ketiga ditemukan dalam percakapan pada tuturan (3). Pada konteks percakapan tersebut salah satu penutur menggunakan kata Bred untuk menyapa lawan tuturnya. Kata Bred merupakan pemendekan dari kata brother. Bentuk sapaan ini digunakan sebagai bentuk rasa hormat kepada seseorang yang sangat akrab.

\section{Proses Pembentukan}

Ada banyak cara yang digunakan untuk menciptakan bahasa prokem, dari yang paling standar sesuai dengan kaidah aturan tertentu, hingga yang paling sulit karena tidak berpola yang sama. Bahasa prokem para pekerja manyeng di Desa Garung Lor, Kaliwungu, Kudus memiliki cara tersendiri dalam memodifikasi kata sehingga terbentuklah bahasa prokem. Berdasarkan hasil penelitian ditemukan dua cara pembentukan bahasa prokem para pekerja manyeng di Desa Garung Lor, Kudus. Dua pola tersebut adalah pola pembentukan kata tunggal dan pola pembentukan kata kompleks. Secara umum proses pembentukan bahasa prokem para pekerja manyeng sangatlah simple, yakni hanya menambahkan suku kata \{ask\} pada setiap katanya. Akan tetapi, proses pembentukan bentuk kata tunggal dan kompleks memiliki perbedaan. Pola pembentukan bentuk kata tunggal adalah dengan menyisipkan suku kata ask pada huruf vokal terakhir dari sebuah kata. Misal pada kata kowe terdapat vokal /o/ dan /e/, pada kata tersebut vokal terakhirnya adalah /e/, maka sebelum vokal /e/ diberikan sisipan ask sehingga terbentuklah prokem kowaske. Lebih jelas dapat dilihat pada ilustrasi modifikasi kata di bawah ini.

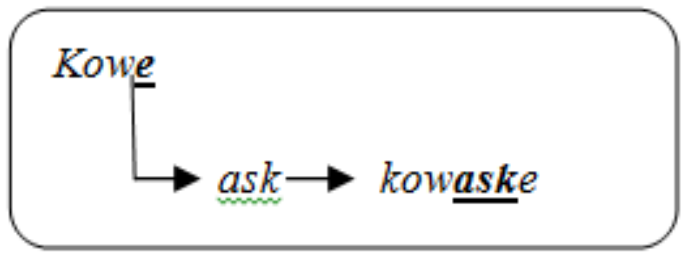

\section{Gambar 1. Proses pembentukan kata tunggal}

Pemilihan sisipan ask tidak memiliki pertimbangan tertentu dalam kelompok ini. Pemilihan ask sebagai bentuk modifikasi hanyalah dianggap sebagai hal unik yang belum pernah digunakan kelompok lain. Sejalan dengan penelitian yang dilakukan oleh Syakur (2017) yang menemukan proses pembentukan bahasa gaul di Bojonegoro dengan menyisipkan suku kata ok pada tengah kata dan membuang huruf vokal dan atau konsonan dibelakang kata. Contoh proses pembentukan kata tunggal bahasa prokem para pekerja manyeng dapat dilihat pada table di bawah ini. 
Tabel 4. Proses pembentukan kata tunggal

\begin{tabular}{|c|c|c|c|c|}
\hline No & Kata & Asal Kata & Proses Pembentukan & Makna Indonesia \\
\hline 1 & ajaska & Aja & aj+ask+a & Jangan \\
\hline 2 & akaski & Aki & $\mathrm{ak}+\mathrm{ask}+\mathrm{i}$ & Accu \\
\hline 3 & akasku & Aku & $\mathrm{ak}+\mathrm{ask}+\mathrm{u}$ & $\mathrm{Aku}$ \\
\hline 4 & ataskum & Atum & at+ask+um & Plastik \\
\hline 5 & dhuwaskit & Dhuwit & dhuw+ask+it & Uang \\
\hline 6 & gelaskem & Gelem & gel+ask+em & Mau \\
\hline 7 & baraskang & Barang & bara+ask+ang & Barang \\
\hline 8 & kowaske & Kowe & kow+ask+e & Kamu \\
\hline 9 & Kerjaska & Kerja & kerj+ask+a & Kerja \\
\hline 10 & laraskang & Larang & lar+ask+ang & Mahal \\
\hline 11 & muraskah & Murah & mur+ask+ah & Murah \\
\hline 12 & oraska & Ora & or+ask+a & Tidak \\
\hline 13 & piraska & Pira & pir+ask+a & Berapa \\
\hline 14 & rugaski & Rugi & rug+ask+i & Rugi \\
\hline 15 & tawaska & Tawa & taw+ask+a & Tawar \\
\hline 16 & tukasku & Tuku & tuk+ask+u & Beli \\
\hline
\end{tabular}

Sementara itu, proses pembentukan kata kompleks tidaklah rumit. Kata kompleks dalam bahasa prokem mengalami proses modifikasi yang sama dengan kata tunggal, yakni dengan menambahkan suku kata ask pada setiap katanya. Proses modifikasi kata kompleks dilakukan dengan cara mencari bentuk dasar dari kata tersebut, kemudian bentuk dasar kata tersebutlah yang akan ditambahi dengan suku kata ask. Proses morfologis yang terjadi pada kata kompleks tidak mendapatkan modifikasi. Imbuhan yang terdapat pada kata kompleks tetaplah dituliskan apa adanya. Misal kata dhempaskulan merupakan bentuk prokem dari kata dhempulan. Proses modifikasi dilakukan dengan mencari kata dasarnya, yakni kata dhempul. Kemudian, kata dhempul mendapatkan penambahan suku kata ask pada vokal terakhirnya, sehingga terbentuklah kata dhempaskul. Kata dhempaskul kemudian mendapatkan proses morfologis berupa akhiran $\{-$ an $\}$, sehingga terbentuklah kata dhempaskulan. Untuk lebih jelasnya, proses pembentukan kata kompleks dapat dilihat pada gambar di bawah ini.

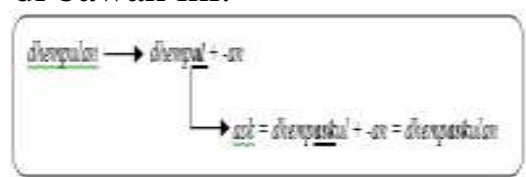

\section{Gambar 2. Proses pembentukan kata kompleks}

Proses modifikasi bentuk kata kompleks tidak memperhatikan penggunaan imbuhan yang melekat. Imbuhan yang ada hanya ditambahkan setelah kata dasar berubah menjadi bentuk prokem. Contoh proses pembentukan kata kompleks dapat dilihat pada tabel di bawah ini. 
Tabel 5. Proses pembentukan kata kompleks

\begin{tabular}{|c|c|c|c|c|}
\hline No & Kata & Asal Kata & Proses Pembentukan & Makna Indonesia \\
\hline 1 & dinyaskang & dinyang & di- + ny+ask+ang & Ditawar \\
\hline 2 & ditembaskel & ditembel & di- +temb+ask+el & Ditambal \\
\hline 4 & angaskele & angele & ang+ask+el+-e & Sulit \\
\hline 5 & baskosku & bosku & $\mathrm{b}+\mathbf{a s k}+\mathrm{os}+-\mathrm{ku}$ & Bosku \\
\hline 6 & hapaskene & hapene & hap+ask+e+ -e & Hpnya \\
\hline 8 & tipaskine & tipine & tip+ask+i+ -e & Tvnya \\
\hline 9 & wegaskahan & wegahan & weg+ask+ah+ -an & Pemalas \\
\hline 10 & ketempaskuhan & ketempuhan & ke- +temp+ask+uh+ -an & Ganti rugi \\
\hline 11 & nempaskuhi & nempuhi & $\mathrm{N}-$ +temp+ask+uh+ -i & Mengganti \\
\hline 12 & laskas-laskasan & Las-lasan & las+ask - las+ask+ -an & Dilas \\
\hline
\end{tabular}

Kata kompleks hasil proses reduplikasi juga mengalami proses modifikasi. Proses modifikasi yang terjadi tidak jauh berbeda dengan modifikasi pada kata kompleks. Proses modifikasi dilakukan dengan melihat bentuk dasar dari kata tersebut. Dari bentuk kata dasar tersebut mendapatkan penambahan suku kata ask. Hal yang sama juga terjadi pada kata kompleks hasil proses reduplikasi yang mendapatkan imbuhan. Proses modifikasi yang terjadi hanya pada bentuk kata dasarnya saja.

\section{SIMPULAN}

Masyarakat yang heterogen membawa dampak pada berkembangnya bahasa era saat ini. Keberagaman masyarakat mengakibatkan variasi bahasa yang ada semakin bermunculan. Keberadaan bahasa prokem menjadi salah satu contoh adanya variasi bahasa di masyarakat. Para pekerja manyeng merupakan salah satu kelompok masyarakat yang memodifikasi bahasa Jawa pada umumnya untuk menjadi bahasa prokem. Berdasarkan penelitian yang sudah dilakukan, ditemukan tiga bentuk bahasa prokem yang digunakan oleh para pekerja manyeng. Ketiga bentuk tersebut, antara lain: bentuk kata tunggal, bentuk kata kompleks, dan bentuk kata sapaan. Proses pembentukan ketiga bentuk bahasa prokem para pekerja manyeng hampir sama satu sama lain. Bentuk kata tunggal dan kompleks dimodifikasi dengan penambahan suku kata ask pada vokal terakhir dari kata tersebut. Sementara untuk imbuhan yang ada pada jenis kata kompleks tidak mengalami perubahan sama sekali. Berbeda dengan kedua jenis kata tersebut, jenis sapaan tidak memiliki acuan pasti dalam proses modifikasinya. Proses pembentukannya lebih pada manasuka dari para penuturnya. 


\section{DAFTAR PUSTAKA}

Al Fithriyah, Nurunnisa. 2013. Variasi Bahasa pada Dialog Film Red Cobex: Kajian Sosiolinguistik. Skriptorium. Vol. 1, No. 2.

Alwasilah, A. Chaedar. 1993. Pengantar Sosiologi Bahasa. Bandung: Angkasa.

Chaer, Abdul dan Agustina. 2004. Sosiolinguistik: Suatu Pengantar. Jakarta: Rineka Cipta.

Chaer, Abdul. 1994. Linguistik Umum. Jakarta: Rineka Cipta.

Istiqomah, Dina Syifa. Dkk. 2018. Analisis Penggunaan Bahasa Prokem dalam Media Sosial. Parole Jurnal Pendidikan Bahasa dan Sastra Indonesia. Vol. 1, No. 5 .

Kridalaksana, Harimurti. 2008. Kamus Linguistik. Jakarta: PT Gramedia Pustaka Utama.

Moleong, Lexy. 2010. Metode Penelitian Kualitatif. Bandung: PT Remaja Rosdakarya.

Ramlan. 2001. Morfologi Suatu Tinjauan Deskriptif. Yogyakarta: CV Karyono.

Sudaryanto. 1993. Metode dan Teknik Analisis Bahasa. Yogyakarta: Duta Wacana University Perss.

Suhardi. 2008. Sintaksis. Yogyakarta: UNY Press.

Sumarsono dan Paina Partana. 2008. Sosiolinguistik. Bandung: Pustaka Pelajar.

Sumarsono. 2002. Sosiolinguistik. Yogyakarta: Pustaka Ilmu.

Suwito. 1991. Pengantar Awal Sosiolinguistik Teori dan Problema. Surakarta: Henary Off Set Solo.

Syakur, Abdul. 2017. Ragam Bahasa Gaul di Pasar dan Terminal Bojonegoro. EDU KATA. Vol 4, No 1.

Waridah. 2015. Penggunaan Bahasa dan Variasi Bahasa dalam Berbahasa dan Berbudaya. Jurnal Simbolika. Vol 1, No 1.

Zulaeha, Ida. 2010. Dialektologi: Dialek Geografis dan Dialek Sosial. Yogyakarta: Graha Ilmu. 